\title{
El garantismo constitucional frente al activismo judicial en la administración de justicia ecuatoriana
}

Fecha de recepción : 04 de julio de 2019 • Fecha de aceptación: 5 de septiembre de 2019 • Fecha de publicación: 10 de septiembre de 2019

\author{
Dr. Gonzalo Enrique Noboa Larrea \\ Universidad Estatal de Bolívar \\ gnoboa@ueb.edu.ec \\ https://orcid.org/0000-0001-5690-7144
}

Dr. Luis Alfonso Bonilla Alarcón Universidad Estatal de Bolívar Ibonilla@ueb.edu.ec https://orcid.org/0000-0003-4186-0739

Dra. Angélica María Gaibor Becerra Universidad Estatal de Bolívar agaibor@ueb.edu.ec https://orcid.org/0000-0001-9723-349X

\section{Resumen}

El nuevo marco legal que se instauró a raíz de la Constitución aprobada el año 2008 ha dado paso a un reconocimiento importante de derechos a las personas en Ecuador. No obstante, en la actualidad dentro del ámbito procesal podría ocasionar una vulneración de los derechos constitucionalmente reconocidos, a causa de la contradicción que se registra entre las normas que promueven el activismo judicial y las que impulsan el garantismo constitucional. En este contexto la metodología empleada en el presente estudio está dada bajo una investigación bibliográfica, la cual permitió establecer un esquema preciso del garantismo constitucional frente al activismo judicial, sobre todo en lo que concierne al debido proceso de la administración de justicia en el país. Por otro lado, también se utilizó el criterio de dos profesionales en el ámbito del Derecho para conocer más de cerca la situación actual del país en relación con las variables objeto de estudio. Finalmente, se puede establecer que las garantías constitucionales constituyen herramientas jurídicas que son utilizadas para de alguna 
manera evitar, frenar o enmendar la violación de cualquier derecho que se encuentre reconocido dentro de la Constitución, mientras que el origen del activismo judicial se remonta a la Edad Media, en donde el accionar mismo del Santo Oficio derivó en el otorgamiento de mayores concesiones a los jueces. Característica esta que aún continúa siendo uno de los fundamentos de la doctrina activista en los actuales momentos, obviamente, a través de argumentos diferentes a los adoptados por la Inquisición.

Palabras clave: activismo judicial, constitución, derecho, garantismo judicial, justicia.

\begin{abstract}
The new legal framework that was established following the Constitution approved in 2008 has given way to an important recognition of rights to people in Ecuador. However, currently within the procedural scope could cause a violation of constitutionally recognized rights, because of the contradiction that is registered between the rules that promote Judicial Activism and those that promote the constitutional Guarantee. In this context, the methodology used in the present study is based on a bibliographical investigation, which allowed to have an accurate outline of constitutional guarantee against judicial activism on everything related to the due process of the administration of justice in the country. On the other hand, the criterion of two professionals in the field of Law was also used to learn more about the current situation of the country in relation to the variables under study. Finally, it can be established that the Constitutional Guarantees are legal tools that are used to somehow prevent, stop or amend the violation of any Law that is recognized within the Constitution, while the origin of Judicial Activism dates back to the Age Media, where, the very actions of the Holy Office led to the granting of greater concessions to the judges. Characteristic that still continues being one of the fundamentals of the activist doctrine in the present moments, obviously, through different arguments to those adopted by the Inquisition.
\end{abstract}

Keywords: judicial activism, constitution, law, judicial guarantee, justice. 


\section{Introducción}

Ecuador es visto, desde una perspectiva jurídica, como un Estado constitucional de justicia y derechos, de acuerdo a lo establecido en la Carta Magna suprema (Aguilar et al., 2009). Así pues, dentro de las innovaciones jurídicas en el ámbito constitucional, se consideró no únicamente la inclusión de mejores garantías a los derechos humanos o a la naturaleza, sino además la creación de un estamento de control e interpretación constitucional de tipo concentrado, llevado a cabo a través de la Corte Constitucional (Jumbo, 2014). Este estamento es considerado como la máxima institución de control e interpretación constitucional y de administración de justicia dentro del país (Zambrano, 2018).

De allí que resulte notoria la presencia del término Estado, que bajo la perspectiva de Vita (2008) hace mención a "una comunidad políticamente organizada en un ámbito territorial determinado. Por lo tanto, una unidad política con instituciones objetivamente diferenciadas que declaran y sostienen el Derecho asegurando el orden a través de una serie de disposiciones que deben ser cumplidas por todos los asociados" (p. 52).

A partir del año 2008, con la aprobación de la nueva constitución, Ecuador adoptó una forma nueva de Estado que ha favorecido que en la actualidad los preceptos constitucionales posean una mayor jerarquía por sobre todo el ordenamiento jurídico (Andrade y Ávila, 2009). No obstante, y a pesar de tener a disposición una Constitución enormemente garantista, no ha sido suficiente para asegurar una efectiva vigencia de los derechos arraigados dentro de la ley, y tampoco ha permitido dar solución en mayor proporción a varios problemas de fondo con los que aún cuenta el sistema de administración de justicia (Rea, 2013).

De esta manera, uno de los principales problemas a los que se enfrenta el Derecho Procesal constituye el grado de intervención que debe tener el juez durante el trámite del respectivo proceso. Situación que ha ocasionado que emerjan dos corrientes plenamente establecidas: la del Garantismo Procesal y la del Activismo Judicial, según tenga el juez mayor o menor protagonismo durante el desarrollo de la causa. Así pues, estas tendencias del Derecho Procesal buscan incidir de forma directa en el trámite de los procesos con la finalidad de conseguir la paz social mediante el reconocimiento de los derechos sustanciales (Salinas, 2007).

Por lo tanto, la búsqueda de una convivencia armónica y de una paz social entre ciudadanos constituyen objetivos muy plausibles que persigue el Estado. Uno de los medios para la consecución de estos fines se fundamenta en una buena actuación del órgano jurisdiccional para resolver cualquier tipo de conflictos y diferencias entre personas al momento que se presenten dichos inconvenientes (Fandiño, 2016).

\section{Las garantías constitucionales}

Según Cabanellas (2015), las garantías constitucionales pueden ser definidas como "el conjunto de declaraciones, medios y recursos con que los textos constitucionales aseguran a todos los individuos el disfrute y ejercicio de los derechos públicos y privados fundamentales que se reconocen" (p. 144). Dicho de otra manera, las garantías constitucionales constituyen herramientas 
legislativas elaboradas con la finalidad de proteger los derechos fundamentales, y presentan una carga valorativa que puede muy bien definir el tipo de sociedad en que rigen.

De esta manera, Zavala (2011) establece que los principios en que se fundamentan estas garantías tienen una justificación externa axiológica o valorativa que se proyecta en el ordenamiento jurídico. Asimismo, Peñafiel, Ordeñana y Zeballos (2018) establecen que "las garantías constitucionales son todas aquellas acciones que de manera expresa o implícita están establecidas por la Ley para salvaguardar los derechos constitucionales y del sistema constitucional".

En este sentido, las garantías constitucionales desempeñan un rol crucial dentro del ordenamiento jurídico del país. Por lo tanto, es deber del Estado salvaguardar los derechos fundamentales y admitir, cada vez que sea procedente, las garantías constitucionales vigentes. De esta manera, los estamentos judiciales están en el deber de prevenir, investigar, sancionar, restablecer e indemnizar el daño producido por la vulneración de los derechos constitucionales y de los convenios internacionales.

\section{Aplicación de garantías constitucionales}

La principal característica del derecho actual es que el poder del Estado se encuentra limitado gracias a que los ciudadanos disponen de las garantías constitucionales, por tal razón, el poder de las autoridades no es discrecional, sino que está en la obligación de cumplir directamente con las disposiciones constitucionales al momento de tomar una decisión, según el Art. 10 y 11 (Asamblea Nacional Constituyente, 2008).

Así pues, de acuerdo al numeral dos del artículo 424 de la Carta Magna vigente, tanto la constitución como los diferentes tratados internacionales ratificados por el país se encuentran al mismo nivel, como normas superiores del ordenamiento jurídico (Blacio, 2014). A partir de ello, los tratados internacionales de Derechos Humanos ratificados por el Estado que reconozcan derechos más favorables a los contenidos en la Constitución prevalecerán sobre cualquier otra norma jurídica o acto del poder público (Asamblea Nacional Constituyente, 2008).

Así mismo, dentro del artículo en mención se establece que "los derechos serán plenamente justiciables"; es decir, este aspecto consiste en que los derechos pueden ser exigidos ante la autoridad jurisdiccional competente para exigir la debida protección. De esta manera, las garantías constitucionales presentan su importancia procedente de la jerarquía de la Constitución dentro del orden jurídico del país (Asamblea Nacional Constituyente, 2008).

\section{La garantía constitucional de la seguridad jurídica y el debido proceso}

La garantía constitucional de la seguridad jurídica tiene su sustento dentro del artículo 82 de la Constitución, donde se estable que "el derecho a la seguridad jurídica se fundamenta en el respeto a la Constitución y/o la existencia de normas jurídicas previas, claras, públicas y aplicadas por las autoridades competentes" (Asamblea Nacional Constituyente, 2008). 
Esta normativa constitucional tiene relación directa con el artículo 25 del Código Orgánico de la Función Judicial, donde se establece que "las juezas y jueces tienen la obligación de velar por la constante, uniforme y fiel aplicación de la Constitución, los instrumentos internacionales de Derechos Humanos, los instrumentos internacionales ratificados por el Estado y las leyes y demás normas jurídicas" (Asamblea Nacional del Ecuador, 2015).

De este modo, el principio constitucional de la seguridad jurídica radica en que tanto las juezas como los jueces brinden confianza y certidumbre sobre la correcta aplicación de la ley a los ciudadanos cuando se encuentren en conflictos legales, dado que, a consecuencia de dicha aplicación, el ciudadano puede prever los efectos y consecuencias de sus actos así como de la celebración de contratos (Peñafiel, Ordeñana y Zeballos, 2018).

\section{Los alcances del garantismo}

El garantismo permite elaborar una reconstrucción parcial del sistema jurídico ecuatoriano a partir de dos premisas fundamentales que guardan relación con 1) el paradigma positivo del derecho constitucional y 2) las funciones garantistas del Estado (Cajas, 2015). De esta manera, en el primer caso, el garantismo acierta al señalar que la estructura del derecho positivo contemporáneo implicaría la primacía de las normas constitucionales por sobre normas inferiores. Tal primacía se denomina en términos kelsenianos nomoestática y nomodinámica.

La primera, la primacía nomoestática, se da mediante contenidos sustanciales, como los valores ético-políticos que informan las normas positivas que exigirían la coherencia, es decir, el respeto a los contenidos sustanciales dentro del desarrollo normativo infra-constitucional. Mientras que la primacía nomodinámica se da en el sentido clásico de reproducción del sistema jurídico, a través de procedimientos que respetan la forma establecida para la realización de actos productivos de normas - reglas procedimentales-(Cajas, 2015).

Por otro lado, en relación a las funciones garantistas del Estado procedentes del paradigma positivista de la Constitución, Ferrajoli (2011) ha mencionado que "la política se transforme en un instrumento de actuación del derecho, sometida a los vínculos que le imponen los principios constitucionales" (p. 47). Es decir, se trata de ver al Estado como un "actor de satisfacción" de los principios constitucionales, donde no se trata de un mandato moral, sino de un reconocimiento de mandatos del derecho positivo. Al menos en el caso ecuatoriano, el constituyente se esforzó por desarrollar esta concepción del Estado y la política como una garantía (Cajas, 2015).

\section{Activismo judicial}

\section{Antecedentes}

Debido a la evolución que ha experimentado la humanidad con el paso de los años es que emerge el Derecho como principio rector de la vida dentro de una sociedad, con la finalidad de indicar e iluminar a través de normas el camino ideal para el desenvolvimiento adecuado de la interacción entre las personas, a fin de garantizar una convivencia sana y pacífica entre pares. 
Bajo el contexto del epígrafe anterior, esta evolución de la humanidad a la par del derecho ha presentado cambios constantes que nacieron del pensamiento de ilustres personajes, quienes trasladaron las diferentes civilizaciones de sistemas dictatoriales y monárquicos a Estados donde se observa claramente la presencia de la democracia, la igualdad de pares ante la ley y el sometimiento a un sistema jurídico como sus bases esenciales (Rea, 2013).

De esta manera, cabe destacar que, aun bajo la normativa de Estados de derecho, la administración de justicia se ha visto guiada por ideologías políticas, lo cual ha generado en varias ocasiones que esta sirva única y exclusivamente como herramienta para el ejercicio del poder, convirtiendo a los diferentes jueces en meros ejecutores de las políticas de turno.

Para Maraniello (2018), el activismo constituye toda "actitud frontal, activa y directa frente a diferentes obstáculos que se pueden presentar en el camino hacia un determinado objetivo" (p. 125) y, por consiguiente, según De Julios Campuzano (2016), un juez activista representa un "magistrado que desprovisto de toda formalidad brega por el cumplimiento de sus propósitos en búsqueda de la verdad jurídica objetiva con respeto de los derechos constitucionales" (p. 34).

Asimismo, Mejía y Pérez (2015) establecen que el activismo judicial hace referencia a la práctica y concepción según la cual el juez se convierte en un limitador y actor subsidiario de los demás poderes del Estado a través de la aplicación de la Constitución y los derechos fundamentales. Asimismo, Rhenals (2014) considera que se refiere a "la creatividad de las sentencias, al protagonismo del tribunal y al aggiornamento del servicio de justicia" (p. 294). Dicho en otras palabras, nos encontramos frente al activismo judicial toda vez que los magistrados hacen interpretaciones novedosas sobre el texto constitucional y con esto envían algún tipo de mensaje a los poderes del Estado y a la sociedad en general.

En el sentido de las anteriores apreciaciones doctrinales, el activismo judicial corresponde al ejercicio de las funciones jurisdiccionales, asumiendo cierto protagonismo en el tema de reconocimiento y protección de garantías de los ciudadanos y por supuesto promoviendo una dinámica fluida de creación de derecho (Larraín, 2013).

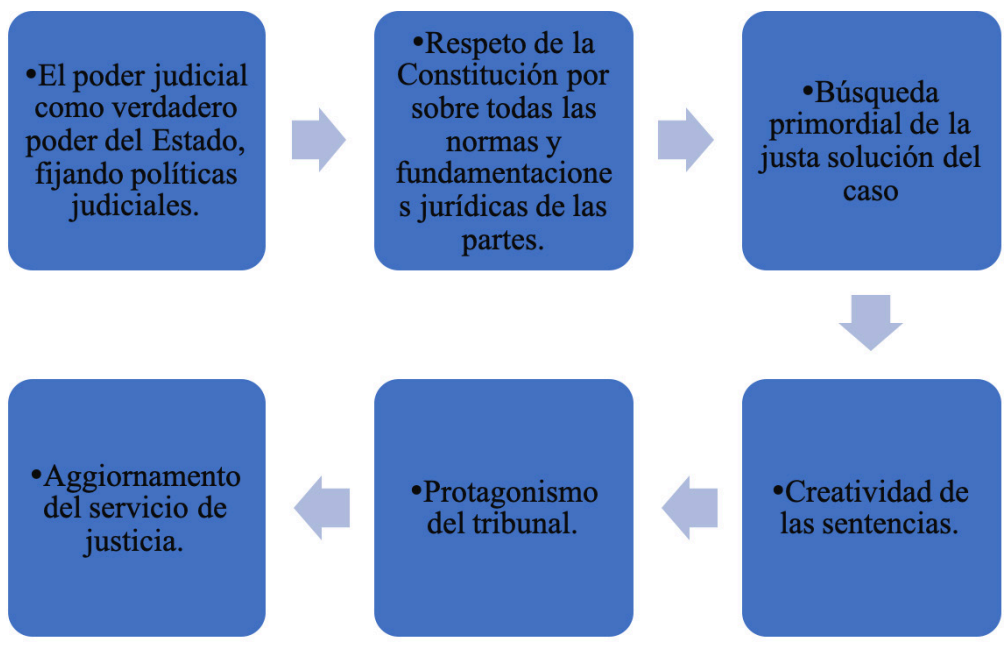

Figura 1. Características del Activismo Judicial. 


\section{Clases de activismo judicial}

Activismo judicial adjetivo. Los juristas que plantean que el activismo judicial únicamente debe tener incidencia adjetiva mantienen la posición de que el juez debe tener mayores atribuciones respecto al proceso mismo (Dávila, 2015); es decir, en su regulación formal, en el control de los presupuestos procesales y en el impulso del proceso sin que las partes lo soliciten (Velasco, 2013).

El activismo judicial adjetivo es ostensiblemente contrapuesto al garantismo judicial, que se caracteriza por sostener que el proceso es un problema entre las partes y, por ello, cualquier conflicto celebrado ante jueces o tribunales se rige por el principio dispositivo (Chamba, 2015). En otras palabras, el proceso debe iniciarse necesariamente a instancia de parte, nunca por iniciativa de un juez, quien debe atenerse a las pruebas presentadas sin tener ninguna iniciativa probatoria dentro de los límites de la pretensión del demandante y la contestación del demandado (Díaz, 2015). Por estas razones, según esta corriente, hacer lo contrario sería convertir al juez en un ente parcializado que se entromete en el derecho material de las partes (Peyrano y Peyrano, 2016).

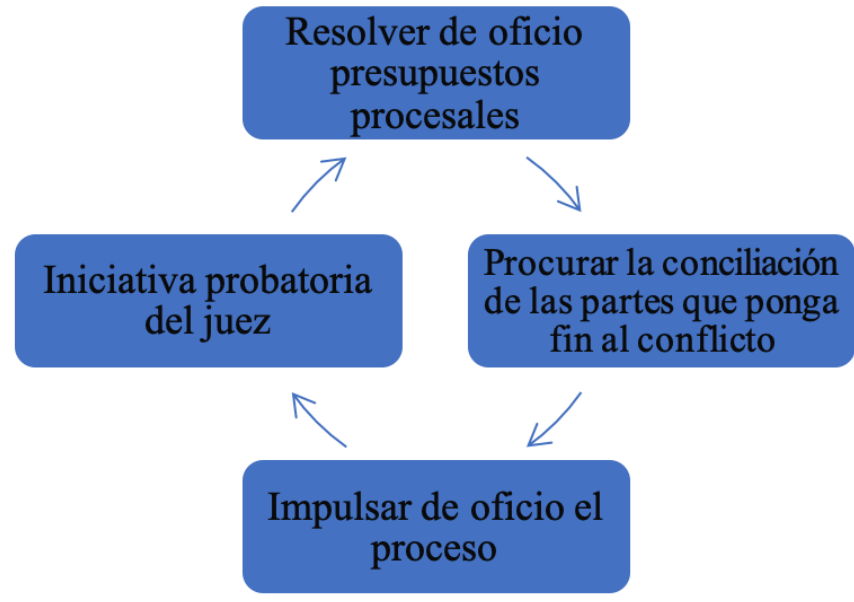

Figura 2. Activismo judicial adjetivo.

Activismo judicial sustantivo. El activismo judicial sustantivo establece que, "cuando la situación lo amerite, el juez está en la obligación de ampliar el alcance y la trascendencia de sus decisiones con la finalidad de garantizar y proteger los derechos de la parte afectada y para dar proyección social a sus sentencias" (Velasco, 2013).

Este tipo de activismo judicial ha ganado fuerza durante las últimas décadas en diferentes países del mundo y, en especial, en América Latina, gracias a la judicialización de litigios o casos de carácter estructural cuya finalidad se centra en garantizar los derechos culturales, sociales y económicos de grupos de personas que en determinado momento han sido afectados por personas naturales, personas jurídicas o hasta por el Estado (Feoli, 2016). 


\section{Efecto en la conducta de grupos e individuos}

\section{Efectos en la opinión pública}

\section{Efectos frente al poder ejecutivo y legislativo}

Figura 3. Activismo judicial sustantivo.

\section{Métodos y materiales}

El estudio se ha hecho a través de una revisión sistemática por medio de revistas indexadas, artículos científicos, mandatos, normativas y legislación, como técnica analítica y exploratoria para tener un esquema preciso del garantismo constitucional frente al activismo judicial sobre todo lo que concierne al debido proceso de la administración de justicia en el país. La metodología propuesta es de revisión bibliográfica-documental. En primera instancia, se fundamentó en un análisis preliminar que ayudó a formular ciertas interrogantes dentro del sistema jurídico del Ecuador. Asimismo, se utilizó el criterio de dos profesionales en el ámbito del derecho para conocer más de cerca la situación actual del país en relación con las variables objeto de estudio.

\section{Resultados}

Como se mencionó en el epígrafe anterior, los resultados obtenidos corresponden al criterio de profesionales del derecho, los cuales se presentan a continuación en la Tabla 1.

Tabla 1

Resultados

¿Considera usted que el control constitucional de la Corte Constitucional implica o representa un mecanismo directo o indirecto de una limitación de poder de los demás órganos de la administración de justicia que conforman la Función Judicial?

Conclusión ¿Por qué?

Dr. Xavier Oquendo Polit

La disposición del Art. 428 de la Constitución de la República que obliga al Juzgador a suspender la tramitación de la causa cuando considere que una norma es contraria a la Constitución o a los tratados internacionales de derechos humanos, y remitir el proceso a la Corte Constitucional para que resuelva sobre su constitucionalidad, es una limitación a las facultades jurisdiccionales que tienen los jueces de dirimir los conflictos que llegaren a su conocimiento aplicando la norma de mayor jerarquía.

\section{Dr. Rodolfo Ceprián Molina}

Desde mi punto de vista, si la Constitución de la República del Ecuador le ha otorgado la atribución a la Corte Constitucional para efectuar un control, este es eminentemente directo, porque proviene de la norma supra nacional, que es jerárquicamente superior incluso de instrumentos internacionales, por lo que dicho control no podría ser indirecto si la fuerza que tiene es un imperativo categórico de la norma constitucional.

Existe una clara limitación
en la administración de
justicia, por cuanto el juez
debería estar facultado a
inaplicar una ley, norma
o disposición que sea
contraria a la Constitución
vigente, así sea una
norma posterior al año
de su promulgación (en
el 2008 ). Por lo tanto, se
recomienda una revisión
desde un punto de vista
constitucional y legal de
dicha atribución.

Existe una clara limitación justicia, por cuanto el juez debería estar facultado a inaplicar una ley, norma o disposición que sea contraria a la Constitución vigente, así sea una noma posterior al año su promulgación (en recomienda una revisión constitucional y legal de dicha atribución.

Fuente: Adaptado de Zambrano, L. (2018), "El control constitucional y la limitación en la administración de justicia en el Ecuador". 
En la actualidad, el activismo es parte de la cultura jurídica del aparato judicial, y aunque en ocasiones ello implique que se profieran fallos polémicos, insospechados, exagerados 0 simplemente contra mayoritarios, lo verdadero es que aquella situación no debe ser una causal de sorpresa; obviamente, siempre que el fallo final no se enmarque en la arbitrariedad y por sobre todo se respeten tanto las garantías y principios constitucionales establecidos (Maraniello, 2018).

No obstante, lo alarmante resulta que la judicatura sea tomada como objeto de influencia de diferentes ramas de poder, impidiéndole tomar sus decisiones con total independencia, y que no se exterioricen fallos que a través de elementos sesgados beneficien de cierta manera, por ejemplo, al Ejecutivo, como se ha observado en diferentes países de Sudamérica con tendencia socialista, en los que alguna Alta Corte ejecuta interpretaciones carentes de argumentaciones y adecuaciones técnicas que dejan notar falacias con claras intenciones ventajistas (Mejía y Pérez, 2015).

Bajo estas consideraciones, la corriente garantista intenta un respeto efectivo a la Constitución aprobada, esencialmente enfocado en los derechos que se refieren al debido proceso (Cajas, 2015). De esta forma justifica su postura de reducción de los poderes que le faculten al juez intervenir en los asuntos de fondo del proceso. No obstante, considera también que el juez sí debería tener las prerrogativas necesarias para la dirección del proceso (Rea, 2013).

\section{Conclusiones}

Las garantías constitucionales constituyen herramientas jurídicas que sirven para evitar, frenar o enmendar la violación de cualquier derecho reconocido dentro de la Constitución vigente en el país, dado que, si no existiesen dichas garantías, los derechos establecidos dentro de la Carta Magna se convertirían únicamente en enunciados sin eficacia ni eficiencia jurídica en la práctica misma; de manera que, en realidad, el ciudadano quedaría en una situación de total indefensión ante la presencia de una determinada violación de un derecho fundamental tipificado y consagrado.

Por otro lado, el origen del activismo judicial se remonta a la Edad Media, en donde el accionar mismo del Santo Oficio derivó en el otorgamiento de mayores concesiones a los jueces. Característica esta que aún continúa siendo uno de los fundamentos de la doctrina activista en los actuales momentos, obviamente, a través de argumentos diferentes a los adoptados por la Inquisición, dado que estos se encuadran dentro del espacio del respeto a los derechos.

Asimismo, si bien el término garantismo procesal no ha sido divulgado y conocido mayormente, tampoco se puede decir que se enmarca dentro de una nueva doctrina, pues este tiene su fundamento dentro del principio dispositivo cuyo origen se encuentra asociado al Estado liberal, el cual fue implementado después de las grandes revoluciones del siglo XIX.

Por su parte, si bien se registran una serie de características propias tanto de la corriente garantista como de la activista, se puede establecer que todas estas buscan argumentos que avalen un aumento o disminución, dependiendo del caso que se maneje, de prerrogativas 
concedidas al juez dentro del desarrollo del debido proceso. De manera que, básicamente, la discusión se enmarca en el análisis del grado de intervención que debe tener el juez dentro del proceso en desarrollo.

Finalmente, la realidad jurídica ecuatoriana establece que en relación con la temática se ha desarrollado una especie de sistema mixto en el cual confluyen tanto la corriente garantista como la activista, situación esta que surge a partir de la vigente Constitución, la cual reconoce al principio dispositivo como uno de los derechos esenciales para la administración de justicia en el país, con lo cual, en inicio, estaría acogiendo la doctrina garantista. No obstante, existen también diferentes textos legales que admiten la actuación judicial de oficio, particularmente en materia probatoria, aspecto que es propio de la corriente activista. 


\section{Referencias bibliográficas}

Aguilar, J. P., Ávila, R., Benalcázar, P., Borja, A., Cordero, D., Dávalos, J., ... Silva, C. (2009). Nuevas instituciones del Derecho Constitucional Ecuatoriano. Latacunga, Ecuador: INREDH, Ed.

Andrade, S., y Ávila, L. F. (2009). La transformación de la Justicia. (Primera Ed). Quito, Ecuador: Ministerio de Justicia y Derechos Humanos.

Asamblea Nacional Constituyente. (2008). Constitución de la República del Ecuador 2008. Montecristi.

Asamblea Nacional del Ecuador. (2015). Código orgánico de la función judicial. Montecristi.

Blacio Aguirre, G. S. (2014). La protección de los derechos en la historia constitucional ecuatoriana. Revista Sur Academia, (2), 6-17.

Cabanellas de las Cuevas, G. (2015). Diccionario jurídico elemental. Buenos Aires, Argentina: Editorial Heliasta, S.R.L.

Cajas, A. K. (2015). El garantismo en el constitucionalismo ecuatoriano. Universidad Andina Simón Bolívar, Ecuador.

Chamba, M. A. (2015). La independencia judicial: entre la utópica posición de la teoría constitucional y la normativa del Ecuador. Universidad Andina Simón Bolívar, Ecuador.

Dávila, P. D. (2015). La acción de protección: vía eficaz para reparación integral por la compra de renuncias obligatorias con indemnización. Universidad Andina Simón Bolívar, Ecuador.

De Julios Campuzano, A. (2016). Itinerarios constitucionales para un mundo convulso. Madrid, España: Dykinson, S.L.

Díaz, R. (2015). El activismo judicial de la jurisdicción constitucional en el marco de la democracia. Justicia Juris, 11(2), 50-57. https://doi.org/10.15665/rj.v11i2.763

Fandiño, M. (2016). Guía para la implementación de mecanismos alternativos al proceso judicial para favorecer el acceso a la justicia. Santiago, Chile: Centro de Estudios de Justicia de las Américas.

Feoli, M. (2016). Judicialización de la política y activismo judicial: una aproximación a América Latina. Revista Latinoamericana de Derechos Humanos, 27(1), 75-98. https://doi.org/10.1109/CISPEE.2013.6701968

Ferrajoli, L. (2011). Garantismo. Una discusión sobre derechos y democracia. Madrid, España: Editorial Trotta.

Jumbo, S. T. (2014). La evolución del Estado Social de Derecho al Estado Constitucional de Derechos y Justicia Social. Universidad Central del Ecuador. 
Larraín, L. (2013). Activismo judicial en Chile. Revista Libertad y Desarrollo, (242), 1-29.

Maraniello, P. A. (2018). El activismo judicial, una herramienta de protección constitucional. Revista de Ciencias Sociales Tla-Melaua, 7(32), 121-165. https://doi.org/10.32399/rtla.7.32.25.

Mejía, J. y Pérez, R. (2015). Activismo judicial y su efecto difuminador en la división y equilibrio de poderes. Justicia, 3(27), 30-41.

Peñafiel, Á., Ordeñana, A. y Zeballos, R. (2018). La garantía constitucional de la seguridad jurídica y su relación con los derechos fundamentales en la república del Ecuador. Revista Multidisciplinaria de Investigación Espirales, 2(22), 39-54.

Peyrano, J. y Peyrano, F. (2016). El activismo judicial. Derecho, (13), 1-8.

Rea Lozano, N. A. (2013). Análisis de doctrinas procesales: activismo judicial o garantismo procesal y su aplicación en la Administración de Justicia en el Ecuador. Universidad de las Américas, Quito, Ecuador.

Rhenals, J. E. (2014). El activismo judicial en el reconocimiento de los derechos fundamentales de los toxicómanos en Colombia. Revista de IUSTA, 13(39), 291-318.

Salinas Rivas, R. (2007). Características del activismo y del garantismo judicial. Revista Iberoamericana de Derecho Procesal Garantista, 5(2), 1-6.

Velasco Mancheno, M. C. (2013). Análisis comparativo del activismo judicial en Estados Unidos de América y Ecuador. Pontificia Universidad Católica del Ecuador, Quito, Ecuador.

Vita, L. (2008). El concepto de "Estado" en la ciencia política moderna. Revista Electrónica Del Instituto de Investigaciones “Ambrosio L. Gioja”, 2(3), 99-111.

Zambrano, L. E. (2018). El control constitucional y la limitación en la administración de justicia en el Ecuador. Universidad Católica de Santiago de Guayaquil, Guayaquil, Ecuador.

Zavala Egas, J. (2011). Teoría y práctica procesal constitucional. (Primera Ed). Guayaquil, Ecuador: Edilex S.A. 